\title{
LOS PÓSITOS DE PESCADORES: LA VIDA DEL PÓSITO DE MOAÑA A TRAVES DE LAS MEMORIAS DE COSTA ALONSO, (1921-1939).
}

\author{
Por \\ CARMEN FERNÁNDEZ CASANOVA
}

\section{INTRODUCCIÓN}

La llegada a mis manos de Apuntes de mi vida societaria. Memorias de José Costa Alonso ${ }^{1}$, me ha permitido conocer una fuente, inédita, rica en datos para el conocimiento del desarrollo institucional del Pósito de Pescadores de Moaña, (1921-1939), que adquiere mayor interés por la carencia de estudios monográficos y, en definitiva, por un escaso estado de la cuestión. Esta realidad y las características de la propia fuente limitan las posibilidades de argumentación y análisis, y condicionan el planteamiento de una hipótesis de trabajo muy ajustada a la letra del documento. El objetivo a conseguir será, pues, dar a conocer los datos aportados por el recuerdo de las vivencias de Costa Alonso, como responsable de la Asociación, mediante una ordenación temática coherente, enlazada por las referencias cronológicas; en fin, un estudio de microhistoria que permite, a

${ }^{1}$ Apuntes de mi vida societaria Memorias de José Costa Alonso,(inédito), comienza en el año 1921, fecha de constitución del Pósito de Moaña, y abarca al menos hasta 1950, aunque este estudio concluya en 1939. No obstante conviene advertir que, en la versión aquí utilizada y para el periodo estudiado, faltan los años 1926, 1928, 1929, 1930, 1931.

"CUADERNOS DE ESTUDIOS GALLEGOS", Tomo XLVI, Fascículo 111, Santiago 1999. 
la vez, superar el marco local en aspectos relacionados con la institucionalización de estas asociaciones de marcado carácter polivalente.

Además de las limitaciones de planteamiento, conviene señalar las de la propia fuente por su autoría y características: la visión subjetiva y unilateral, «las filias y las fobias»..., ingredientes naturales en la elaboración de diarios, memorias... y que, con mayor o menor intensidad, están presentes en los distintos episodios y escenas de la vida societaria, presentados por Costa Alonso. De ahí que quepa la diferenciación entre las aportaciones cuestionables, como consecuencia de la percepción personal sobre personas y organizaciones, y los datos relacionados con el resultado de las dinámicas de desenvolvimiento de los Pósitos que nos permiten hacer el seguimiento del organigrama institucional.

La pluma, en definitiva, es dirigida por José Costa Alonso, pescador de Moaña, católico, hombre de orden, bienquerido por la dictadura primorriverista, que acaba vistiendo el uniforme de Falange, y, sobre todo, un trabajador tozudo e infatigable en favor del Pósito de Moaña, que acaba desempeñando puestos de responsabilidad en los distintos niveles de organización de estas sociedades cooperativas.

\section{El marco societario en la Galicia marinera de principios del siglo $\mathrm{XX}^{2}$}

Como es sabido la desaparición de los Gremios de Mar en 1864 reduce el panorama asociativo dentro del sector pesquero y resta posibilidades de supervivencia a los pescadores, por la labor benéfica y de «ordenación de los recursos» que desarrollan. De cualquier forma, se mantienen en Galicia algunos Gremios reformados como el de Mareantes de Pontevedra, y los de Mar en el Porto do Son, Ares y A Guarda, que cumplen una mínima función mutualista, (atención a la muerte y a la enfermedad). En este tiempo suenan las voces discrepantes de Díaz de Rábago y Alfredo Brañas, y surgen intentos de institucionalizar un asociacionismo mixto, integrado por armadores y pescadores, dentro de una triple vertiente de actuación: mutualista, cooperativa y de crédito. Responden a estos principios la Sociedad Marítima del Berbés de Socorros Mutuos, (1878), promovida por el clero y las autoridades marítimas, y la Asocia-

${ }^{2}$ Este apartado recoge en síntesis la aportación de Dionisio Pereira. Vid, PEREIRA, D. (Coord): Os conquistadores modernos. Edicións A Nosa Terra, Vigo, 1992; pag. 153 y ss.

"CUADERNOS DE ESTUDIOS GALLEGOS", Tomo XLVI, Fascículo 111, Santiago 1999. 
ción Cambadesa de Marineros, organizada por Alfredo Brañas. Sociedades similares, configuradas alrededor de unos objetivos propios de ese viejo modelo, (mixto y representativo de los intereses de un determinado arte, o bien de corte mutualista), viven un momento de expansión entre los años 1899 y 1909; valga como ejemplificación dentro de un período más reducido, el establecimiento de 29 sociedades marineras desde Corme a Miño: Bouzas, Cangas, Moaña, Domaio, Pontevedra, Marín, Meira, Baiona, Ribeira, Cabo de Cruz, Palmeira, Fisterra...

En estos mismos años, en los dos grandes puertos de Vigo y A Coruña y más tardíamente en Marín, aparecen las primeras sociedades de resistencia al socaire de la modernización del sector, manifiesta en la apertura del mercado, medios de producción con mayor capacidad productiva, y la nueva organización del trabajo dentro de un modelo industrial en expansión. Fundamentalmente este asociacionismo ha crecido como resultado del enfrentamiento entre armadores, poseedores de medios de producción, y asalariados, que cuentan con los recursos de la solidaridad societaria. La extensión y organización de las sociedades de resistencia aparecen condicionadas por las características del propio sector: la pervivencia y el peso de la pesca artesanal posibilita la coexistencia de las sociedades de marineros a la parte con las de los tripulantes asalariados de los vapores, (frecuentemente diferenciados en Marineros, Maquinistas, Fogoneros y Patrones), y la convivencia, bajo el techo de un asosacionismo mixto, de patronos y marineros, usuarios de un determinado arte y beneficiarios de una modalidad retributiva a la parte; además la interdependencia de las actividades crea las condiciones de solidaridad y arrastre ante una situación de conflictividad.

Después del conflicto de 1897, los tripulantes de vapores de Vigo establecen su propia sociedad, adscrita a la U.G.T. En 1902 los traineros de A Coruña se reúnen en La Humanidad Libre dentro de la Federación Local Obrera de tendencia anarcosindicalista, para contrarrestar la iniciativa de los patronos-armadores agrupados en El Progreso. Siguen este ejemplo en 1906 los asalariados de los bous que establecen La Unión Marítima, integrada también en la Federación anarquista. Desde Vigo y Pontevedra el asociacionismo marinero se irradia hacia todos los pueblos de la Rías Bajas, favorecido, sobre todo, por la expansión de las nuevas técnicas y relaciones laborales. Sirvan como muestra la creación en Marín de la Alianza Marinera, constituida en 1914 por los tripulantes de los 
vapores y motoras, y, poco tiempo más tarde, la de sus homónimas de Cangas y Moaña; en Bueu se instituye El Adelanto Marinero y La Necesaria en Ribeira.

Debido al peso de la influencia socialista en las Rías Bajas se organiza la Federación Regional de Obreros de la Industria Pesquera de Galicia, presidida por Lorenzo Corbacho, y que integra colectividades de Aldán, Bouzas, Cangas, Moaña, Bueu, Chapela, Vigo, Pontevedra, Portonovo, Sanxenxo, Porto do Son y Ribeira. La Federación cumple por primera vez el papel de coordinadora del sindicalismo de clase en el sector pesquero, atendiendo la ordenación pesquera, la reglamentación de los aparejos en las rías, el asesoramiento de las sociedades en conflicto; no obstante desaparece en el año 1922.

En Coruña, por efecto de la animación de la CNT, se establece en 1915 la Sociedad de Marineros, Fogoneros y Patrones «El Despertar Maríti$m o »$ que incluye a tripulantes de la marina mercante, trabajadores del servicio del puerto y pescadores. Esta tendencia de reunión por encima de la especificidad de la actividad profesional es respaldada en el Congreso de la CNT de 1919 y se refleja en la transformación del Despertar Marítimo en la Sección del Sindicato Unico del Transporte Marítimo-Terrestre que aglutina todas las profesiones relacionadas con tareas portuarias.

La Dictadura de Primo de Rivera supuso el freno y desaparición de muchas sociedades; excepcionalmente mantienen su actividad el Sindicato General de Trabajadores en Vigo y Despertar en Coruña, ambas de inspiración cenetista, animadas por el objetivo de hacer extensiva la obligatoriedad del descanso dominical al sector pesquero con resultado desigual para los dos sindicatos: en Vigo se alcanza en 1926 frente a la impotencia del Despertar, maniatada por la persecución del gobierno en 19.27. La pervivencia de estos centros empuja a la CNT a la creación de la Federación Regional Marítima en 1926, que acaba su actividad a los pocos meses con el encarcelamiento de su secretario, José Villaverde.

El desgaste provocado por la intensa conflictividad vivida en las Rías de Vigo y Pontevedra entre 1914-20, así como el vacío dejado por las asociaciones de resistencia desaparecidas, facilita la institucionalización de otras de inspiración confesional o vinculadas a la derecha, que buscan contrarrestar el sindicalismo de clase con organizaciones dirigidas por personas de orden, armonizadoras del capital y el trabajo. Están dentro de esta tipología la Asociación de Marineros Pescadores de Viveiro bajo el

"CUADERNOS DE ESTUDIOS GALLEGOS", Tomo XLVI, Fascículo 111, Santiago 1999. 
tutelaje de personas conservadoras de la villa, el Sindicato Católico de Trabajadores del Mar de Bouzas y el Sindicato Católico de Marineros de Cangas, ambos de tendencia confesional.

El establecimiento de los Pósitos de Pescadores es otra iniciativa societaria de interés. Se inspiran en las viejas cofradías de Pescadores y se definen como «asociacións cooperativas sen distingo entre armadores e mariñeiros, que arelaban a mellora das condicións de vida, mediante o establecemento de socorros e seguros; a extensión cultural entre os asociados; e a explotación direta da industria pesqueira polos seus protagonistas.(....). Estaban financiados, además das cotas dos socios, pola Caja Central del Crédito Marítimo dependente do Ministerio de Mariña. A composición dos seus órganos representativos era paritaria, adoptando un talante corporativo que procuraba aunar os intereses de armadores e mariñeiros, afastando a estes das organizacións de clase» ${ }^{3}$. El origen o iniciativa de constitución de estas entidades tiene carácter oficial, sigue una trayectoria vertical, de arriba abajo, a cargo de las autoridades de Marina de las que emergen actuaciones personalizadas como la de Alfredo Saralegui, capitán de corbeta, principal propagandista de los Pósitos. Colaboran, también, en su funcionamiento, además de muchos funcionarios de las Ayudantías, algunas personas vinculadas al asociacionismo profesional, e incluso agrarios próximos al radicalismo como Ramón Salgado.

El primer Pósito de todo el litoral español se establece en Cambados el 17 de diciembre de 1917; de aquí se extienden, primeramente, a las Rías de Arousa y Muros, y más tarde por las de Vigo, Pontevedra y el norte de Galicia, con un fuerte aumento en los años de la Dictadura, de tal forma que a la llegada de la República existen cincuenta Pósitos, integrados en la Federación Gallega de Pósitos Marítimos. Como apreciaremos al presentar las Memorias de Costa Alonso, la institucionalización de estas entidades cuenta con la enemiga de las sociedades de resistencia, que veían en ellas un obstáculo para la consecución de su planteamiento de conflictividad en momentos de reivindicación. Así la campaña contra los Pósitos dirigida por la Federación Obrera de Marín junto con las Sociedades de Marineros de Cangas y Moaña son la respuesta al boicot a una huelga de marineros, en 1923, al ser sustituidos por socios de aquéllos. De cualquier forma,

${ }^{3}$ PEREIRA, D. (Coord.) op. cit.; pag. 165.

"CUADERNOS DE ESTUdiOS GALLEGOS", Tomo XLVI, Fascículo 111, Santiago 1999. 
los Pósitos consiguen una implantación aceptable en los pequeños puertos, por su actuación benéfica, aliviadora de la carencia de infraestructuras, -lonjas, puertos...-, de la mala situación económica y de la indigencia educativa de los pescadores mediante el mantenimiento de escuelas, algunas de ellas modélicas en la pedagogía de la formación profesional. Pero si bien se reconoce el papel global y las actividades concretas de los Pósitos, que sustituyen con mayor acierto al asociacionismo mixto tradicional, también se critica la falta de eficacia para transformar las condiciones de vida y de trabajo de los pescadores.

Durante la Segunda República prolifera el sindicalismo de clase en casi todas las villas costeras, aunque los grandes puertos actuarán como cabeceras de la afiliación y de la conflictividad de los núcleos más pequeños, de pesca artesanal, por las múltiples vinculaciones existentes entre las diversas flotas. La conciencia de esta interrelación constituye un factor decisivo para la constitución de la Federación Regional de Industria Pesquera, afiliada a la CNT, que aglutina a casi todos los pescadores sindicados en Galicia que suman los 11.471 en 1932. Los sindicatos anarquistas más importantes son: el Sindicato de Industria Pesquera de Vigo, que en 1932 tiene 2.200 afiliados, el Sindicato de Industria Pesquera de Marín con 1.600, el Despertar Marítimo de A Coruña con 1.500, y con censos similares La Alianza Marinera de Cangas y Solidaridad Marinera de Moaña.......... y así hasta alcanzar a lo largo de la etapa republicana casi todos los puertos de Coruña, Pontevedra y algunos de Lugo. La Confederación Gallega, para ajustarse a la cada vez más compleja realidad de los puertos, se estructura orgánicamente por medio de sindicatos y de la Federación de Industria que reúne a todas las profesiones relacionadas con la pesca; de esta forma abandona la organización a base de sociedades de oficio y consigue mayor efectividad en la dirección de los conflictos. Todo parece indicar que en esta etapa el sindicalismo de clase, (60 sociedades, 1930-36), supera, por primera vez, en número e influencia social al sindicalismo mixto, representado por los Pósitos, (57, 1930-36), y las sociedades mixtas de pescadores, $(4,1930-36)$, con mayor implantación en los puertos pequeños, aunque las corrientes proletarias comienzan a disputar también esos espacios, como se evidencia en los Pósitos de Mugardos y Pontevedra, bajo la influencia del PCE, y el de Cambados en la órbita de la CNT.

El dinamismo de la Federación Regional se manifiesta en la convocatoria de numerosas huelgas en puertos dominados por su tendencia, (A 
Coruña, Vigo, Marín, Cangas, Moaña, Teis, Ribeira, Pontedeume, Bueu....), e incluso en aquellos otros donde no tiene esa posición directora, ( Cariño, Celeiro, Cambados, O Grove, Porto do Son....). La lucha social está protagonizada, fundamentalmente, por los tripulantes de los vapores y motoras, que reivindican mejoras ya planteadas -aumento de salarios, condiciones de trabajo más favorables...-, en los conflictos más prolongados de todos los sectores de la economía gallega.

Se aprecia la extensión de la solidaridad entre los integrantes del sector y partícipes de la misma posición ideológica, sin embargo entre los adscritos a otra tendencia es frecuente la rivalidad y desentendimiento, lo cual dificulta a veces la consecución de una solución favorable de un conflicto. Pero también resulta comprobable a través de las movilizaciones de los puertos de Vigo, Bueu, Cangas, Ribeira, Moaña, Cariño...,que las luchas marineras prenden cada vez más en la sociedad que se identifica con las partes implicadas, comportamiento ya observable en el 1900 en el movimiento social de jeiteros contra traineros, que se incrementa en este momento por la acción de ese sindicalismo de clase, «forza social de primeira orde nas cidades e vilas costeiras galegas», como se aprecia en la huelga y lock-out pesquero del segundo semestre de 1932 en Vigo.

Tampoco abandona la Federación Regional la actividad cooperativa con vocación de supervisión de todos los aspectos de la práctica pesquera mediante la creación en Vigo del Comité de Defensa de la Pesca del Litoral Gallego preocupado por evitar la especulación en la venta de la sardina y el jurel en la lonja; controlar la producción y distribución, eliminando a los intermediarios, para conseguir mejores precios; vigilar el uso de la dinamita; proteger los caladeros con criterio conservacionista; y adquirir los aparejos necesarios para la actividad pesquera.

\section{LA ORGANIZACIÓN INTERNA DE LOS PÓSITOS DE PESCADORES: EL EJEMPLO DE CANGAS}

Los Pósitos se definen en el Reglamento del Pósito de Pescadores de Cangas $^{4}$ como una asociación cooperativa de pescadores que persigue su

\footnotetext{
${ }^{4}$ Los Reglamentos de estas Asociaciones, como los de sociedades de otro signo, recogen una normativa standard que permite la generalización..
}

"CUADERNOS DE ESTUDIOS GALLEGOS", Tomo XLVI, Fascículo 111, Santiago 1999. 
«redención», «extendiendo la cultura entre sus asociados, estableciendo en su favor los distintos seguros sociales y explotando sin el auxilio de intermediarios la industria pesquera». ${ }^{5}$ De acuerdo con estas características, sus objetivos son polivalentes, de índole económica, cultural y de previsión: organizar la venta, exportación y manipulación de los productos de la pesca; adquirir embarcaciones y artes para uso de la asociación; facilitar crédito a módico interés, para la adquisición de los medios de producción necesarios en el ejercicio de la actividad pesquera; aportar cultura general y profesional a los afiliados; además atender a fines de previsión -seguros sociales entre otros-. La Sociedad está sujeta a la inspección de la Caja de Crédito Marítimo a la que ha de comunicar las modificaciones introducidas en el Reglamento.

En su organización interna el Pósito cuenta, como cualquier otra entidad, con tres ejes fundamentales: la Junta General, la Junta de Gobierno y las Secciones. Con criterio democrático, o cuando menos mayoritario, se establece que la Junta General es «el organismo supremo de la Asociación», que «se reunirá ordinariamente en el mes de diciembre», en la fecha más conveniente para la asistencia mayoritaria de los afiliados. Puede tener carácter extraordinario, cuando lo determine la Junta de Gobierno, su Presidente, «o lo pidan la cuarta parte de los socios de número existentes. Cuando éstos sean en número superior a 200, bastará con que lo soliciten cincuenta». Las competencias de las Juntas Generales Ordinarias van de la concreción a la formulación genérica: verificación de votaciones para la elección de la Junta de Gobierno, aprobación de la Memoria de la Sociedad y de las cuentas y balances de las distintas Secciones y de la Asociación en general, y finalmente el debate sobre todas las cuestiones relacionadas con el «régimen, porvenir y gobierno» del Pósito.

La Junta de Gobierno está compuesta por Presidente, Vicepresidente $\mathrm{y}$, al menos, un Vocal-Inspector por cada una de las Secciones, elegidos entre los socios de número; por otros dos Vocales en representación de los socios cooperadores; un Tesorero; un Contador y las Juntas administradoras de las Secciones; además, como situación posible, sin visos de obligación, puede haber dos Vocales del sexo femenino, «en representación de las mujeres que sean socios cooperadores». La normativa establece que el número de miem-

${ }^{5}$ Reglamento del Pósito de Pescadores de Cangas. (Pontevedra, 1921); pag. 1

"CUAdERNOS DE eStudios GALLEGOS", Tomo XLVI, Fascículo 111, Santiago 1999. 
bros de la Junta ha de ser impar, pero con representación paritaria para armadores y «obreros pescadores»: cuando menos dos de cada grupo profesional. Ordinariamente la periodicidad de reunión es mensual, pero con carácter extraordinario puede realizarse siempre que lo solicite un Vocal. La Junta General puede crear una Junta de Gobierno en otro puerto vecino, dependiente y con representación en la Junta de Gobierno principal, si existe un número importante de socios residentes en lugares próximos.

El Presidente de la Junta de Gobierno es el responsable primero de la Sociedad, y, en consecuencia, ostenta su representación. Sus competencias diversas manifiestan su responsabilidad dentro de la Asociación: presidir las Juntas General, de Gobierno, y las reuniones de las Secciones, hacer cumplir el Reglamento y los acuerdos adoptados, abrir y cerrar las sesiones, supervisar los documentos expedidos, ordenar los pagos e ingresos, firmar escrituras y contratos públicos..; asimismo tiene capacidad resolutiva en asuntos de urgencia, con la obligación de informar en la primera sesión de la Junta. El Vicepresidente ejerce las funciones del Presidente por ausencia o enfermedad. El Contador resuelve su papel con atribuciones de supervisor contable: lleva los libros que «prescribe el código de comercio y la ley de Asociaciones», interviene y extiende todos los documentos necesarios para realizar pagos e ingresos, redacta y firma los balances trimestrales y anuales, la memoria anual del estado económico y los presupuestos generales de la Asociación. Al Tesorero corresponde la custodia de los fondos y los efectos de valor pertenecientes a la Sociedad, pero sin autonomía plena, dependiente de la autorización del Presidente y el Contador; entre sus competencias concretas están: la elaboración de libros contables de ingresos y gastos y movimiento general de fondos, la verificación de arqueos mensuales, hacer efectivos los créditos concedidos y los pagos del Pósito......El Secretario, como corresponde, cumple la función de ayudar al Presidente: convoca las sesiones de las Juntas y recoge su desarrollo en las actas, se encarga de la correspondencia, la elaboración de la Memoria y del archivo y control de la documentación... El Vicesecretario sustituye al Secretario por ausencia o enfermedad. Los Vocales deberán integrarse en las comisiones y desempeñar los cargos que se les asignen; en el caso de los Vocales Inspectores velarán por el funcionamiento reglamentario de las Secciones a las que estén adscritos.

En el seno de la Sociedad conviven y se desarrollan diversas Secciones específicas según los objetivos propuestos Todas ellas presentan una orga-

"CUADERNOS DE ESTUDIOS GALLEGOS", Tomo XLVI, Fascículo 111, Santiago 1999. 
nización común: disponen de una Junta Administradora por Sección, integrada por Vocales retribuidos, y ligada orgánicamente a la Junta de Gobierno, a la que debe informar de la marcha de la Sección, (recursos propios, burocracia...). Existe una amplia variedad deSecciones, configuradas por razones de previsión, económicas y culturales: Socorros Mutuos, Embarcaciones, Venta de productos de la pesca, Caja de Crédito, Cooperativa de venta de efectos pesqueros, Cooperativa de consumos, Cultural, Montepio, Exportación y Manipulación de productos de la pesca. La vertiente de previsión es llevada, en primer lugar, por la Sección de Socorros Mutuos, que se responsabiliza de la inspección y administración de la ayuda a los asociados y sus familiares en situación de enfermedad, muerte, paro involutario, pérdida de los medios de producción, (embarcaciones, artes), e incluso higiene; se complementa con la Sección de Montepio que canaliza la liquidez obtenida por otras actividades seccionarias a la concesión de seguros de vejez e invalidez a los socios con cierta veteranía. La modalidad económica se articula alrededor de un doble criterio complementario: la captación y distribución de recursos. Persiguen la generación de recursos sin perder de vista la ayuda a los afiliados: la Sección de Embarcaciones que explota las embarcaciones compradas o alquiladas y tripuladas por los socios, la de Venta de los productos de la pesca y la Cooperativa de consumos encargada de la oferta de todo lo necesario para el mantenimiento de los útiles de pesca, y además, como desideratum, de lo demandado en là vida diaria. La distribución de liquidez es objetivo de la Sección Caja de Crédito, que proporciona préstamos a los socios para la adquisición, reparación y entretenimiento de los medios de producción, (embarcaciones, artes..), e incluso en caso de necesidad, para la propia subsistencia. Por último, la Sección Cultural pretende «una constante acción moral y educadora» sobre los asociados mediante la impartición de clases de conocimientos generales y profesionales, de cursos prácticos de capacitación, conferencias, proyecciones, sesiones cinematográficas, además de la dirección y administración de servicios, (cafetería, restaurante...), y diversiones.

En el capítulo de socios se presentan tres clases: de número, cooperadores y adjuntos. Reúnen condiciones para ser de número, «los inscriptos de Marina, mayores de veinte años y menores de sesenta, que se dediquen o hayan dedicado a la pesca y los armadores de las embarcaciones que pa- 
guen su tanto por ciento a la Asociación». ${ }^{6}$ Esas circunstancias deben concurrir en los cooperadores, si bien esta categoría está abierta, además, «a las mujeres dedicadas a cualquier faena de pesca, y las madres viudas, esposas, hijas viudas o solteras, y viudas de socios de número o de quien lo haya sido hasta ausentarse de la localidad. Todos ellos deberán ser mayores de veinte años». ${ }^{7}$ Para ser socio adjunto es necesario tener las relaciones de parentesco arriba expresadas, ser mayores de doce años y no pasar de veinte. Todas las categorías deberán pagar las cuotas correspondientes, que constituyen el medio de vinculación más determinante con la entidad, y atenerse a la normativa del Reglamento en el ejercicio de derechos y deberes, y respetar los acuerdos de las Juntas.

El Pósito se concibe como una Asociación, «ajena a toda idea política, religiosa o de lucro». El apoliticismo, junto a la ausencia de vínculos de parentesco, son condiciones a cumplir por los concursantes a cargos retribuidos que han de ser nombrados por la Junta General.

Un Inspector, propuesto por la Junta General a la Caja Central de Crédito Marítimo, tiene potestad para revisar la documentación y asistir a las sesiones.

\section{EL PÓSITO DE MOAÑA A TRAVÉS DE LAS MEMORIAS DE COSTA ALONSO}

\section{La constitución del Pósito de Moaña}

José Costa Alonso comienza la recreación de su andadura como pescador comprometido con la institucionalización de los Pósitos de Pescadores, narrando la dificultad de su establecimiento en Moaña. Es el verano de 1917 y Costa se entera por su amigo, Manuel Rodríguez Riobó, que Alfredo Saralegui, oficial de la Armada, tiene el propósito de organizar un Pósito de Pescadores en Moaña. En esta ocasión el proyecto no sale adelante por la falta de colaboración de los armadores más modestos. Cuatro años más tarde, (abril de 1921), se produce la segunda intentona sin éxito: Gregorio

\footnotetext{
${ }^{6}$ «De los socios. Su clasificación». Ibídem, pag.15-16.

${ }^{7}$ Ibídem.
}

"CUADERNOS DE ESTUdIOS GALLEGOS", Tomo XLVI, Fascículo 111, Santiago 1999. 
Fernández Ballesta, oficial auxiliar de la Armada, enviado por la Caja Central de Crédito Marítimo, (hoy Instituto Social de la Marina), recibe el desplante de la Alianza Marinera ${ }^{8}$, sociedad de resistencia de inspiración socialista, que en la Junta celebrada el cinco de mayo, sobre todo por la intervención de los diputados Anguiano y Cordero, rechaza la propuesta de constituirse en Pósito. Por fin en mayo Costa Alonso culmina el encargo de organizar «un germen» de Pósito, que en su primera Junta General, con la presencia de Gregorio Fernández Ballesta, le nombra presidente. La constitución definitiva de la Asociación tiene lugar el 5 de junio; en esta sesión inaugural, Ballesta pide a los dirigentes de la Alianza Marinera, con sentido de la anticipación «que no combatan al Pósito, ya que esta Asociación de cultura, cooperación y previsión, era ajena a toda lucha social, política y religiosa, lo que al parecer prometieron».

\section{Las relaciones con la Sociedad de resistencia}

Las relaciones con la Alianza Marinera ocupan un lugar importante en el recuerdo de Costa, en una narración detallada y, por supuesto, unilateral, en la que se trasluce el malestar e incluso cierto resentimiento, va presentando las estrategias y actuaciones de la sociedad de resistencia en el intento de mermar la afiliación del Pósito de Moaña.

Cuenta Costa como al poco tiempo del establecimiento del Pósito de Moaña, la Alianza Marinera emprende una campaña dirigida a la exclusión de los socios del Pósito de las tripulaciones de los barcos, mediante coacciones a los armadores, a los que plantean la imposibilidad de que afiliados de ambas sociedades compartan tareas dentro de una misma embarcación. La continuidad de estas actitudes alimenta en el verano de 1921 un ambiente de odios y rencores: se suceden las quejas, desatendidas con frecuencia, al Gobernador Civil y al Comandante de Marina, por

\footnotetext{
${ }^{8}$ La Alianza Marinera se constituye como sociedad de resistencia en febrero de 1919: «los tripulantes, que habían sufrido toda clase de explotaciones y atropellos en aquel tiempo de ganancias fabulosas a la pesca de la sardina en la costa de Portugal, se organizan en una formidable Asociación de resistencia que había de ser la dueña de los destinos del pueblo durante varios años, apelando a toda clase de medios para salir triunfante, lo que casi siempre conseguía, iniciándose entonces las luchas, los odios y rencores, que aún perduran en esta Villa.»... Apuntes de mi vida societaria. (Memorias de José Costa Alonso); pag. 3
}

"CUADERNOS DE ESTUDIOS GALLEGOS", Tomo XLVI, Fascículo 111, Santiago 1999. 
los atropellos cometidos por la sociedad de resistencia. Estas situaciones, como si se tratara de un sistema de contrapesos, van minando la afiliación del Pósito y, a la vez, engrosando la de la Alianza, que, para mayor control, exige a sus socios una certificación de cese en la Asociación antagonista bajo la amenaza de una sanción pecuniaria entre 100 y 150 pesetas. La disolución del Pósito toma visos de probabilidad, entre otras circunstancias porque el Ministro de Marina deniega la solicitud de enrolar en los barcos de pesca a sus asociados. La concesión de 2.000 pesetas por la Caja Central de Crédito Marítimo para la adquisición de material de enseñanza, supone una escasa inyección de vitalidad para superar la situación de postración.

A comienzos de 1922 la Alianza trata de boicotear la actividad de la lancha del Pósito mediante amenazas a la tripulación y a los vapores para evitar su traslado a los lugares donde realizan las capturas. Estas circunstancias y la situación de debilitamiento que viven otras asociaciones de este carácter, como la de Vigo, contribuyen a mantener el pesimismo sobre su futuro.

Las tensiones vividas por las dos sociedades se trasladan a la sociedad de Moaña, de tal forma que resulta difícil actuar sin tomar partido por uno de los antagonistas. Costa Alonso, por ejemplo, cuenta en sus Memorias como el armador Manuel Villaverde Palmás, propietario de la primera casa ocupada por el Pósito, les desaloja a pesar de pagar puntualmente el alquiler -30 pesetas mensuales.

En este ambiente enrarecido por la rivalidad de las asociaciones, se produce una intervención contradictoria de Costa Alonso, significativa del respaldo oficial con que contaba: al saber la intermediación de laAlianza Marinera, hace todo lo posible para que el Ministerio de Marina desestime la petición de los propietarios de chinchorros para abolir la prohibición de uso de este aparejo, defendida por Emiliano Iglesias, diputado del partido republicano radical. Ante la promesa de integración de esos modestos armadores en el Pósito cambia el sentido de su actuación ante el Ministerio, reivindicando ahora el uso de chinchorros con el apoyo de Saralegui y Barreras Massó.

El 13 de junio de 1922, le toca el turno a las rederas: la Alianza Marinera «envió una comisión a visitar a los armadores para que no llamaran al tranajo a las «atadoras» (rederas) que trabajaran en lo sucesivo en los aparejos del Pósito, notificando de antemano a estas para que se abstuvie- 
ran de trabajar en dichos aparejos» ${ }^{9}$. La respuesta de las mujeres es desigual: la mayoría se abstiene, pero otras, las mejores, en opinión de Costa, intentan mantener su actividad; situación que les conduce a un largo tiempo de paro desde el 13 de junio al 9 de octubre. al reducirse la posibilidad de trabajo a la oferta del Pósito. Los armadores, que, a pesar de la advertencia, emplean a las rederas, son boicoteados durante el mismo tiempo. Este enfrentamiento genera nuevas vicisitudes: visitas continuas al Gobernador Civil; concentración en Moaña de la Guardia Civil, insultos, vejámenes, atropellos......Costa Alonso habla de la imposibilidad de salir a las faenas de pesca. «Las pobres mujeres fieles al Pósito eran perseguidas, insultadas, vejadas......La Guardia Civil tenía que protegerlas de las acometidas del populacho, con la pasividad de los menguados armadores, pero no se amilanaban. Su conducta era digna y ejemplar». ${ }^{10}$ El conflicto se solucionó meses más tarde, ( 9 de octubre de 1922), por la intervención del nuevo Gobernador, Emilio Llaseras, mediante una fórmula poco favorable y gravosa para los de la Alianza, que en esta confrontación con el Pósito han perdido 8.000 pesetas.

La proximidad de Costa a las autoridades es un hecho en agosto de 1922, cuando la Alianza Marinera celebra un mitin en el que intervienen Saborit, Waldo Gil, Zapata y Romero Piñeiro. Costa Alonso asiste con instrucciones secretas del Gobernador, Antonio Lloret y Lloret, para que «le denunciara cuanto mereciera denunciarse». En sus Memorias reproduce las palabras de Saborit: «Hay que luchar. Hay que tener agallas. En esta casa hay honradez., hay buena administración. Aquí nadie roba. No hacer caso a las calumnias que se lanzan por ahí». «Waldo Gil dijo que el Jefe del Gobierno (Sánchez Guerra) era un chulo. Y Romero Piñeiro, al hacer el resumen, dijo que había que continuar siempre adelante, apelando al puñal y la pistola si los del Pósito se interponían en el camino». ${ }^{11} \mathrm{Al}$ final del mitin se canta la Internacional. Costa Alonso denuncia estas expresiones y se abren diligencias judiciales que obligan a la realización de un careo entre Romero Piñeiro y Costa, que acaba con la agresión del presidente del Pósito al de la Alianza, como respuesta a su actitud cínica

\footnotetext{
${ }^{9}$ Op. cit., pag. 11

${ }^{10}$ Ibídem, pag. 12

${ }^{1}$ Apuntes de mi vida..., pag. 15
}

"CUADERNOS DE ESTUDIOS GALLEGOS", Tomo XLVI, Fascículo 111, Santiago 1999 
de negación de todo lo que había dicho en el mitin. En este ambiente de tensión resulta «natural la acción de la última escena»: «Un poco más tarde, en la calle, cuando se agruparon alrededor de Romero unos 30 hombres dispuestos a agredirme, este dijo que sí, efectivamente, que era cierto lo que había denunciado». ${ }^{12}$

$\mathrm{Al}$ terminar el otoño y cesar la costera en Portugal, los de la Alianza emprenden una nueva estrategia contra el Pósito, que persigue, de manera pertinaz, el mismo objetivo: dejar de trabajar cuando se incorporen sus rivales, con lo cual obligan a los armadores a no admitirlos. Costa Alonso denuncia esta situación a las autoridades de Marina que sancionan con multas a los armadores, y éstos para evitarse problemas deciden pagar a los del Pósito aunque no acudan al trabajo. Ya comenzado el año 1923 los pescadores, cansados de ese procedimiento, acuerdan admitir a los socios del Pósito, lo que, en opinión del presidente, constituye un triunfo para esa Asociación y un fracaso para la Alianza.

También en 1923 se detiene y encarcela a Romero Piñeiro por resultar sospechoso del incendio del vapor «Marzo». Asimismo es requerido por el Ayudante de Cangas, el dueño del vapor «Elena» que se había negado a llevar a los socios del Pósito, aunque en el interrogatorio niegue cualquier connivencia con la Alianza Marinera.

Desde hace un año se producen bajas de algunos pescadores en laAlianza Marinera, seguidas de altas en el Pósito, y que Costa Alonso atribuye a «divergencias y otras causas» ${ }^{13}$. En coherencia con su habitual criterio de actuación, denuncia estas coacciones ante el segundo comandante de Vigo, Joaquín Jáudenes.

Las tensiones vividas en este momento salen a la luz en los pasacalles de las comparsas de carnaval integradas por los de la Alianza Marinera, que tratan de poner en evidencia al presidente del Pósito, aludiendo, en concreto, al conflicto de las atadoras:

\footnotetext{
${ }^{12}$ Ibídem

${ }^{13}$ Costa Alonso ejemplifica estas «divergencias y causas» en el caso de los hermanos Álvarez Rivas, sufridores de las represalias de Lorenzo Corbacho, presidente de la Alianza, una vez superado el destierro, que trata de frenar su marcha a Málaga para enrolarse en un barco de Curbera, mediante la presión a responsables y patronos. Apuntes de mi vida..., pag. 19-20
}

"CUADERNOS DE ESTUDIOS GALLEGOS", Tomo XLVI, Fascículo 111, Santiago 1999. 
«El Pingandiño pateño

Padre de la colección

Amigo de todas ellas

Maestro de dirección» ${ }^{14}$.

Como respuesta a las continuadas provocaciones, la Junta de Gobierno del Pósito acuerda lanzar unas hojas «divulgativas», de propaganda, dirigidas, aunque sin destinatario expreso, al pueblo de Moaña:

«A las innumerables calumnias, a las intolerables malas artes que desde la fundación de esta Sociedad se han lanzado contra ella por determinada colectividad, hemos dado la callada por respuesta; a los cruentos ataques que se han dirigido contra nosotros hemos contestado con una pasividad casi criminal, pues no hay ser, por pacífico que sea, que no se defienda de las acometidas innobles del enemigo que ataca por la espalda. Pero las cosas han llegado a ser hasta tal punto intolerables que nos vemos en la necesidad de rebatir, aunque solo sea por una vez, la serie de insidias lanzadas en un mal escrito prospecto que se repartió el 27 de febrero último, autorizado por la Directiva de la Alianza Marinera y ratificadas unos días después en un periódico socialista de Vigo, por su corresponsal, o lo que sea, en esta Villa». ${ }^{15}$

Además en estas hojas de propaganda se valora la repercusión favorable del Pósito, incluso para la Alianza, que, por temor a la competencia, anula las sanciones que impone a sus afiliados; $y$, además, refuta las imputaciones que hace la Sociedad de resistencia a la Asociación cooperativa:

«Las armas más calumniosas de que se valen para combatirnos son las de que este Pósito es político y está mangoneado por caciques, es decir, que con el ropaje de que se reviste la Alianza pretenden sus mangoneadores cubrirnos a nosotros. Pruebas cantan: por el local de las Pillas desfilaron innumerables oradores políticos todos ellos y por

\footnotetext{
${ }^{14}$ Ibídem, pag. 21

${ }^{15}$ Ibídem, pag. 22
}

"CUADERNOS DE ESTUDIOS GALLEGOS", Tomo XLVI, Fascículo 111, Santiago 1999. 
lo tanto caciques, y en sus discursos no hicieron más que propaganda política; jamás conferenciaron en bien del pescador, ni dictaron normas eficaces para encauzar la vida del marinero y procurar el bienestar común. Los copiosos ingresos que obtuvo la Alianza se invirtieron en propagandas electorales y en defender a quienes por haber vulnerado las leyes cayeron en sus justicieras redes. A esto se redujo toda la labor que hizo la Alianza durante tanto tiempo, y en estos benéficos fines fueron invertidos muchos miles de pesetas». ${ }^{16}$

Por contra el Pósito desarrolla actividades específicas propias de sus obligaciones reglamentarias, ajenas a la propaganda política y postulaciones electorales, sin aplicar sanciones en las relaciones con sus afiliados. En el balance final Costa Alonso se hace estos interrogantes: «En resumen: la Alianza en cuatro años que lleva de vida ¿qué hizo?. ¿Dónde están los beneficios que indudablemente debía de haber obtenido con tantos miles de pesetas?. ¿Se cultiva la inteligencia de los socios o sus hijos?. ¿Se les socorre legal y reglamentariamente?». Frente a esto, el Pósito, aún con trabas importantes que no tuvo la Alianza,... «en 21 meses creó una Escuela, tiene Secciones de Socorros, ha concedido préstamos a sus asociados, compró una lancha con aparejos y por último va a crear una sección de suma importancia: la Caja de Crédito». Además se trasmite un desideratum y un reto: «Que no se nos persiga ni calumnie, que nosotros no le hacemos la guerra a nadie. Y para los que no hacen más que difamarnos, ahí va un reto: que se deje en libertad de acción a los pescadores de Moaña, para que trabajen como, donde y con quien les convenga, y si dentro de un año no hay en el Pósito más socios que en la Alianza, lo disolveremos». ${ }^{17}$

En la primavera de 1923 llegan a Pontevedra Lerroux y Emiliano Iglesias para gestionar la libertad de José Romero Piñeiro; una vez conseguida ocurrirá el gran recibimiento como acontecimiento puntual, pero lo más reseñable es la significación de este suceso como punto de partida de una breve etapa de división entre romeristas y corbachistas en el seno de la Sociedad de resistencia. En medio de ese pugilato se celebra una Junta

\footnotetext{
${ }^{16}$ Ibídem, pag. 23

${ }^{17}$ Ibídem, pag. 24.
}

"CUADERNOS DE ESTUDIOS GALLEGOS", Tomo XLVI, Fascículo 111, Santiago 1999. 
General, en la que se elige presidente a Manuel Rodríguez Pérez, (Ralo). Todo esto le resulta «sumamente agradable» a Costa Alonso y le permite «abrigar la risueña esperanza de que el Pósito iba a quedar tranquilo», aunque, durante un tiempo, el Ayudante de Marina de Cangas, ganado por la Alianza, no atienda «convenientemente» las pretensiones de Costa.

Sorprende la escasa entidad de las razones aportadas en las Memorias para explicar las actuaciones que provoca el advenimiento de la dictadura de Primo de Rivera, (13 de septiembre de 1923). Cuentan que se decreta la clausura de la Alianza Marinera, la detención de sus dirigentes, «según parece por irregularidades halladas en los libros de dicha sociedad», y la paralización de la construcción de la Casa del Pueblo. También a finales de ese año Alfredo Saralegui convoca una Asamblea de todos los Pósitos de España, donde se acordó pedir nueva ayuda al «poder público».

Una vez disuelta la Sociedad de resistencia, Costa Alonso mantiene una actitud de resentimiento contra la Alianza, denunciando, una vez revisados los libros de cuentas, una contabilidad poco cuidada, donde pudo detectar, entre otras irregularidades, un desfalco de 1935 pesetas. Asimismo el conocimiento de los Libros de Actas de la Sociedad, le permiten destacar, de manera parcial, la existencia de una gran diversidad de sanciones por incumplimiento de acuerdos, que, en opinión del presidente del Pósito, son demostrativas «del fanatismo e incultura de los componentes de la sociedad de resistencia.....»

\section{El Pósito en la sociedad local: sentido societario y actuaciones} políticas

A través de las Memorias se evidencia la carencia de expectativas favorables para el desarrollo societario en la sociedad de Moaña, a lo que contribuye la gestión poco exitosa de la Alianza Marinera y del Pósito de Pescadores de Vigo. Esta percepción hace inútiles los esfuerzos de Costa por incrementar la aceptación del Pósito que tropieza con la apatía y maledicencia de los pescadores: «las cosas más fantásticas y absurdas se decían contra mi. Que el Pósito era del Estado, que luchaba por mi conveniencia y que todo era un engaño».

El establecimiento del Retiro Obrero en las embarcaciones pesqueras, debido a las gestiones de Rivera, de Cangas, encienda los ánimos en contra del presidente del Pósito de Moaña: los armadores le consideran «su

\footnotetext{
"CUADERNOS DE ESTUDIOS GALLEGOS", Tomo XLVI, Fascículo 111, Santiago 1999.
} 
ruina y la causa de todos los males que sufría el pueblo», y la Caja Regional lo culpa de «apático y negligente, de no velar por los intereses y el bienestar de los pescadores». Esta situación propicia la actitud contraria de todos los armadores a mantener la ayuda al Pósito del medio por 100.

(.....) «Todo esto de remediar desgracias, de enjugar lágrimas y de aliviar miserias era para ellos de muy poco valor. Solo les preocupaba unas pesetas que cada año o cada trimestre les obligaban a pagar, por mandato de la Ley. Y a pesar de sus apuros y de su modestia, en sus fiestas familiares y en su porte, la inmensa mayoría distaba mucho, pero muchísimo, de demostrar esa condición humilde y de pobreza que constantemente demostraban los tripulantes de sus modestas embarcaciones, de cuya suerte poco o nada se preocupaban». ${ }^{18}$

Parece que el espíritu asociativo va prendiendo en la sociedad de Moaña tal como se desprende de la iniciativa de una peña de pescadores para el establecimiento en 1927 del Recreo Marítimo-Obrero, sociedad recreativa, que preside, a propuesta de sus promotores, Costa Alonso.

En sus Memorias Costa recoge algunos desacuerdos y rivalidades entre las comunidades de agricultores y pescadores en la sociedad de Moaña, por cuestiones nimias, como el conflicto, surgido por la atribución unilateral por la comunidad de agricultores de la adquisición de una imagen de la Virgen del Carmen que en realidad había sido comprada por suscripción entre pescadores y agricultores.

Establecida la Segunda República, en 1932, cuando el Pósito ha consolidado su institucionalización en la sociedad de Moaña surgen nuevas dificultades en el cumplimiento de sus objetivos. Se produce «un nuevo y pavoroso conflicto social», como consecuencia de la modificación del Reglamento de la Mutualidad de Accidentes de Mar y Trabajo, introducida por el Ministerio de Trabajo, y que obliga a los armadores al pago de un gravamen del $2 \%$ sobre la venta de la pesca. En la confusión de cualquier conflicto colectivo se buscan culpas y culpables entre las referencias más próximas, que en este caso recaen en Saralegui y Costa Alonso. «Hubo explosión de petardos, talas de cepas, insultos, abusos, luchas

${ }^{18}$ Apuntes de mi vida.., pag. 53

"CUADERNOS DE ESTUDIOS GALLEGOS", Tomo XLVI, Fascículo 111, Santiago 1999. 
enconadísimas y excesos de todas clases». Ese ambiente de tensiones sociales y políticas se mantiene a lo largo de 1933. En 1934 el triunfo de las derechas hace posible el cambio de la normativa sobre las primas en el Reglamento de la Mutualidad de Accidentes de Mar y de Trabajo que determina su deducción del monte mayor y no de las aportaciones de los armadores. Esta resolución actúa de cortafuegos del conflicto social que sacude Moaña en esos últimos años.

La revolución de octubre deja la secuela de la represión en la villa; con la detención de los maestros nacionales, Victor Sánchez Mártil «y otro de Coya».

En febrero de 1936 se preparan las elecciones a Cortes, Costa Alonso participa en la campaña a favor de Pascual Diez de Rivera, Marqués de Valterra, que presenta su candidatura por Pontevedra y como defensor «de la causa católica»:

«El Sr. Marqués de Valterra se presentaba también como candidato por esta provincia. Y como iba a defender la causa católica, yo no vacilé un momento en entrar en acción, empezando primeramente cierta campaña en la prensa de Vigo, en pro de su candidatura. Y ya en vísperas de las elecciones, yo y el Sr. Meléndez, en el coche de este, hicimos un recorrido hasta El Grove, a donde llegamos ya muy anochecido, encontrando a muy pocos kilómetros del pueblo al candidato también de derechas Sr. Guisasola, el cual, según nos informaron, fue recibido muy hostilmente, tal era la fiebre izquierdista que allí, como en todas partes, existía, llegando incluso a arrojarle piedras. $\gg^{19}$.

Cambados, ganado por las fuerzas de izquierda, resulta el punto más conflictivo de su recorrido propagandístico; Costa relata con minuciosidad esta experiencia en sus Memorias:

«Ya bastante anochecido y una vez terminada nuestra misión en Villanueva de Arosa, el Sr. Marqués de Valterra mostró deseos de ir a Cambados. Y yo, dándome perfecta cuenta de lo que iba a ocurrir, le indiqué que no sería muy prudente hacerlo, ya que en otra ocasión,

${ }^{19}$ Ibídem, pag. 70

"CUADERNOS DE ESTUdIOS GALLEGOS", Tomo XLVI, Fascículo 111, Santiago 1999. 
cuando acompañado del Sr. Comandante de Marina de Villagarcía visité dicho pueblo, los pescadores se comportaron muy mal. Pero don Pascual Diez de Rivera, muy amablemente, me respondió que nada ocurriría y que mis reparos solo obedecían a un infundado miedo, y ante esto acepté el viaje. Llegamos a Cambados, yo, el Sr. Marqués, el Sr. Meléndez y un ingeniero naval, al parecer amigo del Sr. Marqués. Antes de llegar al Pósito de Pescadores, ocupando toda la avenida, había gran numero de personas esperándonos. Su actitud era francamente de hostilidad, llegando como pudimos al local del Pósito con ánimo de hablar, como lo habíamos hecho en otros pueblos, quedando en la calle mis acompañantes, y yo, no demostrando temor alguno, aunque lo tenía y muy grande, resueltamente entré y pregunté por el Presidente, presentándose el Vicepresidente, el cual me preguntó no en buena forma lo qué deseaba. Está aquí el Sr. Marqués de Valterra -le he dicho-y desea hablarles Su contestación fue de pura hostilidad, y, como obedeciendo a una consigna, con cierta violencia, fueron agrupándose en mí alrededor, no vacilando en dirigirse a mí en actitud amenazadora, mas, como mejor podía, diciéndoles que yo también era pescador, que no era político y que no habíamos ido allí sino con ánimos de saludarles, los fui calmando en parte, pudiendo a muy duras penas abrirme paso y ganar la puerta para unirme con los tres señores, mis acompañantes,....Ya yo en el coche, sin detenernos, salimos de aquel infierno, oyendo gritos de ¡Fuera!. ¡Abajo las derechas!... ${ }^{20}$

Inmediatamente después del Alzamiento, transcurridos los primeros meses de la Guerra Civil, Costa Alonso logra disuadir de su empeño a un grupo de falangistas y a un destacamento de marinos, dirigido por un Teniente de Navío, que pretenden clausurar el Pósito de Moaña, por malos informes, como ya lo habían hecho con el local de la disuelta Solidaridad Obrera y la recién establecida Casa del Pescador. De cualquier forma, algunos Pósitos de la zona, considerados rojos son clausurados y detenidos sus directivos. El maestro, Ramón Cabirta Otero, de Moaña, es otro más en el censo de perseguidos.

${ }^{20}$ Ibídem, pag 70-71.

"CUADERNOS DE ESTUDIOS GALLEGOS", Tomo XLVI, Fascículo 111, Santiago 1999. 
La carencia de recursos, consecuencia de la situación de guerra, empuja a Costa a afiliarse a la Falange, donde alcanza el cargo de Secretario de la Delegación Local:

«Y quiero decir, en honor de la verdad, que el programa de la Falange me gustaba, la teoría de tal idea era admirable para mí, pero lo que hicieran algunos militantes me repugnaba en extremo. Mas como la alimentación y la salud de mis hijos pesaban grandemente sobre mi ánimo, me decidí a solicitar mi ingreso, no como militante sino como adherido. Mas el Jefe Local, d. Luis Castells, todo un senor caballero, que, dentro de tantas cosas censurables, logró mantenerse con las manos y la conciencia limpias, me rogó fuera militante diciéndome que la Falange no era, ni podía ser lo que muchos hicieron, viéndome obligado, no de buen gusto, a aceptar. Ingresé, pues en Falange en noviembre de 1937...». ${ }^{21}$

El ascenso social de un pescador: el protagonismo de Costa Alonso en el entramado institucional de los Pósitos

En su Apuntes, Costa cuenta con minuciosidad el desarrollo institucional del Pósito de Moaña y su proyección, a través de la representación de su presidente, dentro del organigrama estatal de estas asociaciones.

Durante la dictadura Costa estrecha su relación personal con Alfredo Saralegui, aprovechando cualquier circunstancia para la aproximación al propagandista de los Pósitos que resultará fundamental para consolidar su presencia en las instituciones. La visita a Vigo de Primo de Rivera y Saralegui, a finales de julio de 1924, es una buena ocasión para el conocimiento personal; tal como lo revive el presidente en las Memorias:

«Y el día 28 fuimos a Vigo una nutrida comisión del Pósito de Moaña, hallando al gran sociólogo sentado a la puerta del Hotel Universal, sin nadie acompañarlo. La prensa local de Vigo había anunciado que le sería impuesta la Gran Cruz de Beneficencia, que, por peticiones de los Pósitos, le había sido concedida, más como Enrique Bayón, Presidente del Pósito de Pescadores de dicha ciudad, se en-

${ }^{21}$ Ibídem, pag. 73

"CUADERNOS DE ESTUDiOS GALLEGOS", Tomo XLVI, Fascículo 111, Santiago 1999. 
contraba injustamente enojado contra el Sr. Saralegui, hizo cuanto pudo para que el acto de la imposición se desluciera todo lo posible. Cuando nos encontramos con dicho señor, lo hallamos bastante contrariado, agradeciendo en extremo la visita y las palabras de gratitud y respeto que le hemos prodigado..».(...)

«Y por la tarde de aquel día el Marqués de Estella y D. Alfredo Saralegui, acompañados de gran número de representaciones llegaron a bordo del «Caramiñal» al muelle de Moaña, donde emocionado, por falta de hábito y por haberme dado cuenta de las personas que tenía delante de mí, le di la más cordial bienvenida al Sr. Saralegui. Más éste, en un tono familiar tan suyo, me rogó saludar en nombre del Pósito de Moaña al Marqués de Estella, lo que hice y creo que bastante regular. Formando parte del acompañamiento venía también el exdiputado D. José Barreras Massó, el cual al darse cuenta que lo había visto y no lo había saludado hizo esta exclamación: ¡Ah Costa infiel i. No se daba cuenta en aquel momento, que el no saludarle y haberle demostrado siempre cierta frialdad e indiferencia, obedecía a no habernos facilitado el aparejo que le hemos pedido para el barco tripulado por el Pósito, cuando nos hacía tanta falta y éramos cruelmente perseguidos, después de habernos ofrecido siempre la mayor ayuda y mayor protección. $»^{22}$.

El día 29 de julio Alfredo Saralegui, acompañado del Ayudante de Marina de Muros, D. Severino Comix Sixto y del Presidente del Pósito de Pescadores de Puentedeume, visita Moaña, con efecto muy positivo para la marcha del Pósito. Costa Alonso aprovecha esta circunstancia para comunicar a Saralegui su deseo de dejar la Presidencia, por el abandono en que tiene su trabajo personal y la subsistencia de su familia; no obstante basta el ruego del sociólogo para retirar la propuesta y recobrar «nuevos bríos para luchar en favor de la Asociación». La devoción que el Presidente del Pósito de Moaña profesa a Saralegui queda manifiesta en la determinación de asistir en Vilaxoán, a pesar de la oposición familiar, al acto de su condecoración con la Gran Cruz de Beneficencia, concedida por el Gobierno.

${ }^{22}$ Apuntes de mi vida...., pag. 36

"CUADERNOS DE ESTUDIOS GALLEGOS", Tomo XLVI, Fascículo 111, Santiago 1999. 
ción, con aceptación por su parte, a diferencia de lo que había ocurrido en las Asambleas de Coruña, (1925), y Vigo, (1926); el cargo de Secretario Contador recae en Antonio Iglesias Rodal, del Pósito de Cangas, y el de Tesorero en José Carvajal Quiroga, inspector local del Pósito MarítimoTerrestre de Tirán; además se establece en Cangas la capitalidad de la Federación. Costa, como asistente más «homenajeado», es nombrado, también, vocal de la Caja Regional Gallega de Previsión y representante de Galicia en la Confederación de Pósitos Marítimos.

La sustitución de Amador Bravo en la Ayudantía de Marina de Cangas por el Capitán de Corbeta, Carlos de la Piñera Tomé, amigo de Alfredo Saralegui, y entusiasta, ejerciente, de la obra de los Pósitos Marítimos, resulta positiva para la Asociación de Moaña. Atendiendo a la petición de Costa Alonso, Carlos de la Piñera plantea a los armadores reunidos en el Pósito de Moaña la necesidad de sus aportaciones para la buena marcha de la sociedad cooperativa; haciendo gala de una actitud inusual hasta ese momento acuerdan conceder el medio por ciento de la venta de la pesca, como aparece reflejado en el acta:

«En el Pósito de Pescadores de Moaña, y con el objeto de que todos sepan la inversión que se da al medio por ciento que conceden los armadores, se nombra una comisión inspectora que presidirá el Sr. Ayudante y la cual componen los señores Manuel Cancelas Pena, Primitivo Costa Chapela y Manuel Villaverde Palmás, y suplentes José del Rio Santomé, Francisco Villaverde Boubeta y Manuel Cancelas Graña. Todos conformes firman en Moaña a 2 de noviembre de 1925». ${ }^{26}$

Esta nueva aportación permite la expansión de las actividades del Pósito.

Por primera vez Costa Alonso asiste a la reunión del Consejo Directivo de la Caja Central de Crédito Marítimo que se celebra en el Ministerio de Marina, donde estaban instaladas las oficinas de la institución. Entre los recuerdos que aporta Costa de ese viaje destaca esta ingenua descripción:

${ }^{26}$ Ibídem, pag. 47

"CUADERNOS DE ESTUDIOS GALLEGOS", Tomo XLVI, Fascículo 111, Santiago 1999. 
«Lo que más me admiraba era ver con tanta complacencia al Sr Saralegui cuando hablaba de mi modesta persona. no avergonzándose nunca en presentarme a los más altos personajes, antes al contrario notaba en él verdadera satisfacción en hacerlo. Y a este respecto recuerdo perfectamente que fuimos juntos los dos en el metro, desde la Plaza de Santo Domingo hasta la calle de Alcalá, donde se hallaba instalada la Dirección General de Navegación y Pesca, siendo la primera vez en mi vida que había viajado en tal forma, estando con el natural azaramiento por ver donde me hallaba y la clase de mi acompañante. Ya en la Dirección General, el insigne sociólogo despachó unos asuntos......Y cuando nos disponíamos a abandonar el edificio se acordó de que no me había presentado al Director General. Inmediatamente, por espontánea voluntad suya, dimos la vuelta diciéndome que tenía un verdadero placer en presentarme, haciéndolo así. El Director General, cuyo cargo lo desempeñaba entonces el Contralmirante D. José González Billón, 'me recibió con extremada amabilidad. El Sr. Saralegui, en su presencia, no cesó en prodigarme toda clase de elogios, lo cual me desconcertaba. Entre otras cosas le dijo que era un modesto pescador y que podía llegar muy lejos si contaba con ayuda y protección.

Todo aquello -quiero confesarlo ingenuamente-me producía un efecto no muy agradable, pues me daba perfecta cuenta, o al menos así lo creía, de mi pequeñez y de mi insignificancia. Hasta lamentaba que el Sr. Saralegui hubiera formado de mí tal concepto, por que sabía iba a quedar mal..». ${ }^{27}$

Están presentes en la reunión: el Ministro de Marina, d. Honorio Cornejo Carvajal, que ejerce de presidente; d. Alfredo Saralegui Casellas, como Secretario General, y como vocales el Director General de Navegación y Pesca, d. José González Billón; el Jefe de la Sección Económica de la Caja Central y alto funcionario de Hacienda, d. Rafael Riaño López; el jefe de la Sección Jurídica de la misma, d. Juan Espejo Hinojosa, del Cuerpo Jurídico de la Armada; el Jefe de la Sección Social, R. Rodolfo Viñas Arcos; los representantes del Instituto Nacional de Previsión, d. Alvaro

${ }^{27}$ Apuntes de mi vida..., pag. 48-49.

"CUADERNOS DE ESTUDIOS GALLEGOS", Tomo XLVI, Fascículo 111, Santiago 1999. 
López Núñez y d. Felipe Gómez Cano, el señor Forcat, del que Costa no especifica cargo, y d. Ventura Morales Pérez, representante de los Pósitos Marítimos.

La impresión que produjo a Costa Alonso la entrada en el lugar de la reunión, refleja la emoción e inseguridad de la persona que accede a un ambiente desconocido y reconocido como superior:

«El encargado del ascensor, como si yo fuera también uno de aquellos personajes que estaban reunidos, con todo respeto abrió la puerta penetrando en su interior, siendo la primera vez en mi vida-así lo confieso- que subía en tal forma. Ya en la antesala del salón donde tenía lugar la reunión del Consejo Directivo, el portero me preguntó qué deseaba, haciéndole ver mi condición de Vocal de dicho Consejo. Inmediatamente me condujo al lugar de la reunión. El corazón me latía apresuradamente. El momento era para mí de gran emoción, de gran solemnidad. Con aquella tan especial situación de ánimo me presenté delante de los reunidos....»

Aún sin la emoción que en aquel momento me embargaba, por mi falta de hábito, me hubiera resultado muy difícil hacer en tal instante un buen papel, como suele decirse, pero mucho más difícil me resultaba hacerlo bajo la enorme impresión que por completo me dominaba, viéndome solo en aquel sitio para mi tan desconocido, en aquel lugar tan regio, esplendoroso, con un derroche de luz y de lujo, todo lo cual contribuía a que me considerara más insignificante, más empequeñecido.». ${ }^{28}$

La segunda reunión del Consejo Directivo se celebra en el mes de diciembre. Las dietas recibidas, (125 pesetas por viaje), constituyeron una inyección revitalizante para la precaria economía de la familia Costa.

En estas fechas es destituido el alcalde de Moaña, Ernesto Carballo García, y nombrado para sustituirle, Ricardo Simil Silva, maestro nacional jubilado; en su equipo de concejales figura Costa Alonso, que renuncia al cargo, alegando sus múltiples ocupaciones, aunque la razón real es

${ }^{28}$ Ibídem, pag. 49-50.

"CUADERNOS DE ESTUDIOS GALLEGOS", Tomo XLVI, Fascículo 111, Santiago 1999. 
el rechazo a una sustitución injusta y, sobre todo. a la actitud poco favorable de Simil hacia el Pósito de Moaña.

En 1927 la Caja Central de Crédito Marítimo, por acuerdo de la Comisión Permanente, encarga a Costa Alonso la organización de los Pósitos de Pescadores de Vigo, desaparecido por mala gestión, y Redondela; para este último caso, al menos, fracasan rotundamente los variados intentos de establecimiento ${ }^{29}$.

En ese mismo año La Confederación Nacional de Pósitos Marítimos, a través de una comisión presidida por Costa, no consigue el favor de Alfonso XIII, en el momento de su visita a Vigo, para solicitar del Estado una ayuda de 5.000.000 de pesetas con objeto de promocionar la pesca del bacalao; Costa Alonso narra el fracaso de los diversos intentos de acercamiento al monarca:

"A fines del mes de septiembre de aquel año -creo que el día 27llegó a Vigo S.M.. El Rey D. Alfonso XIII. Yo tenía el encargo de la Confederación Nacional de Pósitos Marítimos de ir a verlo al frente de una comisión de pescadores, reuniéndose dicha comisión, marchando a Vigo el día de la llegada. Nuestra misión era entregarle un escrito solicitando la ayuda del Estado para obtener un crédito de 5000000 de pesetas para fomentar, por medio de la Confederación, la pesca del bacalao. Pero el primer día de la llegada no nos fue posible lograr nuestro intento, por mucho que lo hemos gestionado. El profesor del Pósito de Pescadores de Cangas, D. Modesto Novelle, ensayó a los alumnos de la Escuela de dicho Pósito, cantando un himno al Rey delante de la Casa Consistorial de Vigo, acompañados de la música del Regimiento de Murcia, en uno de cuyos balcones se hallaban el Rey y la Reina.

Al día siguiente fuimos a bordo del acorazado Jaime I donde se hallaba el Rey, habiendo visitado al Comandante de dicho acorazado, no logrando tampoco nuestro intento de poder hablarle, pues en todas partes hemos hallado dificultades y grandes tropiezos. Un poco más tarde hubo una recepción en el Ayuntamiento de Vigo, a donde fui. Y hallándome hablando con el exdiputado D. José Barreras Massó,

${ }^{29}$ Ibídem, pag. 55.

"CUADERNOS DE ESTUDIOS GALLEGOS", Tomo XLVI, Fascículo 111, Santiago 1999. 
al pie de la escalera, bajó el Rey, saludando a dicho Sr. y hablando con él pocas palabras. Y yo que formaba grupo con ellos permanecí callado por que nadie me presentó, siendo esto todo lo que se logró» ${ }^{30}$.

Ya en la Segunda República, Costa nos deja testimonio, en 1932, de la frecuente relación con el Instituto Social de la Marina, de sus constantes viajes a los puertos como enviado de aquella entidad, y sobre todo de la enorme vitalidad que cobran los Pósitos: reorganización de los ya disueltos, constitución de las Agrupaciones Comarcales de Pósitos Marítimos de Galicia con sede en Ferrol, A Coruña, Vilagarcía y Vigo, entre otras. También por estas fechas empieza a funcionar la Asociación Nacional Mutua de Riesgo Marítimo de las embarcaciones de las listas $3^{\mathrm{a}}$ y $4^{\mathrm{a}}$, creado por el Instituto Social de la Marina y apoyado con entusiasmo por Saralegui. La consecución del seguro de las embarcaciones tropezó con el recelo y la resistencia de los armadores, superados por la tenacidad de Costa, que logra hacer una Junta en Cangas.

La actuación de Saralegui que logra canalizar una pequeña parte de la subida (10 céntimos) del petróleo a favor de la flota pesquera, resulta muy favorable para la expansión de las mutualidades dentro del sector: con la ayuda de la Confederación Nacional de Pósitos y del Instituto Social de la Marina se crea el Secretariado Cooperativo de los Pescadores, al que se asigna un céntimo por cada litro de carburante; el otro céntimo queda para los Pósitos. Cuando el Secretariado Cooperativo cuenta con un capital de 50.000 pesetas establece como sección la Mutualidad de Accidentes de Mar y de Trabajo, organizada centralizadamente con la sede en Madrid y delegaciones en el litoral. Costa es el encargado de la puesta en funcionamiento de las Delegaciones en Galicia, que con esfuerzo, una vez superadas las resistencias pasivas de los dueños de embarcaciones y tripulantes, se van implantando en todos los puestos de Galicia.

En junio de 1932 se celebra una Asamblea de Pósitos Marítimos en Santiago de Compostela, a la que asiste, entre otros, Saralegui. En opinión de Costa en esta reunión se manifiesta «cierta» rivalidad entre los Pósitos del norte y del sur de Galicia, que responde a un sentimiento de

\footnotetext{
${ }^{30}$ Ibídem, pag. 55.
}

"CUADERNOS DE ESTUdiOS GALLEGOS", Tomo XLVI, Fascículo 111, Santiago 1999. 
envidia por los cargos que «inmerecidamente» desempeña, manifestación de una campaña que tiene en la prensa de extrema izquierda y en la actuación de algunos maestros de Orientación Marítima sus máximos exponentes, y que crean un ambiente poco favorable para la actividad del presidente del Pósito de Moaña, a quién imputan la condición de católico y monárquico.

«En mi recorrido continuado por los puertos, tenía que soportar palabras que me molestaban mucho y que tanto me hacían sufrir, pues se dirigían contra los sentimientos más arraigados en mi conciencia, sin encontrar, excepto en Villajuán de Arosa, una nota de simpatía hacia mis arraigados ideales ${ }^{31}$.

En este año de 1932 se disuelve la Confederación Nacional de Pósitos Marítimos por su mal funcionamiento.

Por su parte La Junta de Jefes del Instituto Social de la Marina decide ampliar la zona de competencia de Costa Alonso como inspector costero desde Finisterre a Portugal, con la gratificación mensual de 150 pestas más 25 «para gastos de escritorio».

En mayo de 1933 la Dirección de la Mutualidad de Accidentes de Mar y Trabajo promueve la celebración de una Asamblea en Moaña, convocada por Costa para nombrar un representante en Galicia. Es elegido casi por unanimidad el presidente del Pósito, que renuncia irrevocablemente, al manifestar su oposición un maestro; una muestra más de la actitud poco conciliadora de este colectivo con nuestro hombre.

Como suele ser habitual, en el verano de 1933 tiene lugar en A Coruña una Asamblea de Pósitos Marítimos, en la que se ratifica a Costa en el cargo de Presidente de la Federación de Pósitos Marítimos de Galicia, a pesar de las expectativas de desconfianza creadas por las actitudes de los representantes del norte.

Resulta significativo comprobar como las instituciones encargadas de la organización y dirección del sector marítimo se implican en una campaña a favor de la candidatura de Saralegui para diputado por el partido radical en la circunscripción de Pontevedra en las elecciones de octubre

\footnotetext{
${ }^{31}$ Ibídem, pag. 59
}

"CUADERNOS DE ESTUDIOS GALLEGOS", Tomo XLVI, Fascículo 111, Santiago 1999. 
de 1933. Luis Fernández de la Rica, funcionario de la Mutualidad de Accidentes de Mar y de Trabajo escribe una carta a Costa, firmada además por Juan Iborra, de Valencia, representante de los Pósitos del Sur y Levante en el Instituto Social de la Marina, en la que le expresa la necesidad de que se una al partido radical y haga propaganda a favor de Saralegui. Eiroa, alcalde de Cangas por ese partido, manifiesta a Costa el mismo talante de exigencia cuando éste recaba su apoyo para la candidatura de Saralegui:

«Es V. desleal al Sr. Saralegui-me dijo-si no labora en favor de todos los candidatos del Partido, pues si va tan solo a luchar por la candidatura de dicho Sr., olvidándose de los otros candidatos, nosotros también nos olvidaremos de Saralegui. Además V. cobra un sueldo del Instituto Social de la Marina y tiene la obligación de hacer cuanto le ordenen» ${ }^{32}$.

De cualquier forma, según nos narra en sus Memorias, Costa se mantiene fiel a sus principios que le distancian del Radicalismo por ser contrario a sus ideales y «a los eternos destinos de España».

Este asunto se supera al cambiar Saralegui su circunscripción electoral de Pontevedra a A Coruña, si bien, finalmente, no consigue suficiente respaldo electoral para su acta de diputado.

En el mes de octubre de 1933 la Junta Central de Pósitos Marítimos, (antes Consejo Directivo), nombra a Costa miembro de la Comisión Permanente del Instituto Social de la Marina lo que le obliga a mantener los viajes mensuales a Madrid, tal como lo hacía habitualmente en su condición de integrante del Consejo Marítimo hasta que la representación se organiza con criterios de diferenciación entre la Galicia Norte y la Galicia Sur. (pag. 63).

En 1934 se llega al acuerdo de apertura de la Casa del Pescador de Vigo, al permitir la impartición de las enseñanzas religiosas para aquellos alumnos que lo deseen; la inauguración tiene lugar en el mes de febrero de 1934, con la asistencia de Saralegui, Marqués de Valterra, Viñas, Costa Alonso. También en Moaña se lucha por conseguir este mismo objetivo.

${ }^{32}$ Ibídem, pag. 62.

"CUADERNOS DE ESTUdIOS GALLEGOS", Tomo XLVI, Fascículo 111, Santiago 1999. 
El 4 de abril se produce un cambio en las competencias del presidente moañés: por orden ministerial cesa como Inspector Costero por incompatibilidad con el nuevo cargo de Secretario Regional del Secretariado Cooperativo e Inspector de la Mutualidad de Accidentes de Mar y de Traba$j o$, con un implemento sustancial en el sueldo.

En las visiones que Costa Alonso aporta del difícil recorrido como hombre defensor y trabajador por los Pósitos, no faltan las rivalidades y las insidias personales. En este sentido, nos cuenta como el intercambio de pareceres y la amistad, surgidos en sus visitas a Vigo, entre el Marqués de Valterra y Joaquín Meléndez Romero, neófito en el mundo de la pesca, provoca el distanciamiento en su relación con el Marqués; a esta circunstancia hay que añadir la constante queja del presidente del Pósito de Moaña por la campaña injusta que se le hace desde la prensa de izquierdas.

En el verano se celebra una gran Asamblea de los Pósitos de Pescadores en la «Casa del Pescador» de Vigo, para solemnizar su inauguración. En esta reunión Costa presenta su renuncia irrevocable a la presidencia de la Federación de Pósitos Marítimos de Vigo, cargo que había desempeñado «a satisfacción de todos» durante siete años, «para ver si se atenuaba esa campaña»; a propuesta del saliente es nombrado Francisco Diz Viñas, presidente del Pósito de Pescadores de la isla de Arousa.

La revolución de octubre repercute en las instituciones pesqueras del Ministerio del Trabajo: el hecho de que la tripulación del buque Turquesa, sorprendido con un transporte de armamento para los revolucionarios, estuviera asegurada en la Mutualidad, y que Eladio Fdez Egocheaga, diputado de las Cortes Constituyentes y Director de la Mutualidad de Accidentes de Mar y Trabajo, no fuese ajeno a ello, precipita su fulminarte destitución y una breve carcelación. Recuperada la libertad, Egocheaga inicia una importante campaña contra Saralegui a través de circulares enviadas a los Pósitos y demás entidades del litoral; de la contraofensiva se encarga Costa, utilizando los mismos métodos de disuasión y propaganda.

«Y creo haber logrado fruto con ello, ya que cuantos esfuerzos hizo el Sr. Egocheaga no dieron resultado alguno, pero ciertos señores, que se hacían pasar por íntimos del Sr. Saralegui, con vistas a poder desplazarlo para ocupar su puesto, sacaban fruto de todo esto, 
culpándole, desde luego injustamente, de izquierdista, de convivir con socialistas y revolucionarios, sin fijarse que el gran sociólogo tenía también en su obra a sacerdotes y a personas de extrema derecha» ${ }^{33}$

En 1935, el Jefe de la Sección Social del Instituto Social de la Marina y encargado del Secretariado de los Pescadores, intenta transformar esta entidad en una Cooperativa Nacional de Pescadores, para lo que convoca una Asamblea General en Madrid, donde Francisco Díz Viñas actúa como representante de los Pósitos del Sur de Galicia. Esta misma Sección Social apoya a Costa para el cargo de Secretario-Contador de la $\mathrm{Fe}$ deración de Pósitos de Galicia, pero esta virtual propuesta no llega a convertirse en nombramiento en la Asamblea General de Vilaxoán por las intrigas de Víctor Sánchez, profesor del Pósito de Coiro. Una vez creada la Cooperativa Nacional de Pescadores se piensa también en Costa para el cargo de Secretario de la Región Gallega y Representante, en definitiva, de esa entidad, por lo que Montero, Secretario para la parte norte de Galicia del Secretariado Cooperativo, es cesado. Las protestas de los Pósitos de A Coruña obligan a hacer la oportuna rectificación, quedando Costa como Delegado de la Cooperativa en Galicia y Montero como Subdelegado. También se encarga al presidente moañés la puesta en marcha de las Delegaciones de la Cooperativa y de las Delegaciones del Banco Popular de Crédito como Sección de la Cooperativa.

En agosto de 1935 se celebra una importante Asamblea de Pósitos de Pescadores en Cillero, presidida por Saralegui. Una vez concluida, Costa y Saralegui visitan los Pósitos existentes entre Cillero y Foz, en los que el sociólogo es acogido con simpatía, y establecen Delegaciones de la Cooperativa de los Pescadores.

En 1936 se encarga a Iborra, de Valencia, y a Costa Alonso la elaboración de un estudio del nuevo Reglamento de la Pesca Marítima, trabajo que iniciaban en Madrid cuando estalló la Guerra Civil.

Durante la Guerra Civil, en enero de 1938, se constituye en Burgos una Ponencia de Ordenación Pesquera en la que participan: Antonio Pazos y Tomás Taracido, de Marín, Augusto Bacariza, de Santiago, un representante de la Organización Sindical de Málaga, Joaquín Vidal Gargallo,

\footnotetext{
${ }^{33}$ Ibídem, pag. 66.
} 
de Santander, José $\mathrm{M}^{\mathrm{a}}$ Zumalácarregui, y Costa Alonso. La realidad de esta Ponencia se debe a la iniciativa de Vidal Gargallo, que supo transmitir su idea y convencer a Alejandro Gallo, Presidente de la Comisión de Trabajo de la Junta Técnica del Estado, transformada en pocos meses en Ministerio de Organización y Acción Social, al que pertenecerán Costa, Vidal, Bacariza..., como auxiliares interinos. El Marqués de Valterra, con el beneplácito de Suances, Ministro de Industria y Comercio, organiza otra ponencia en Bilbao, presidida por él mismo, en pugilato con la de Santander. Conseguida la pacificación, viene la unificación: al final se superan rivalidades y malos entendidos y surge una única Ponencia con sede en Santander, presidida por el Marqués. La historia de los trabajos de Santander está jalonada en las Memorias de Costa, por la narración de sus penurias económicas, causadas por la falta de retribución, situación que le lleva a la indignación y enfrentamiento con el Marqués de Valterra:

«Ya yo sabía que la visita de Vds. era para esto -nos ha dicho-, piensen en España y déjense de pedir dinero. Estas palabras me produjeron viva indignación, $y$, un poco descompuesto y sin poder dominar los nervios, le contesté fuera de tono: Ya pensamos en España, pero debe saber, Sr Marqués -le he dicho-que si V. se viera en nuestra situación haría lo mismo que nosotros. Luego cruzamos otras palabras y salimos de allí de muy mala manera». ${ }^{34}$

Al fin, el cobro de las tan reivindicadas dietas, permite a Costa regresar a Moaña y, una vez allí, conocer la constitución en Cambados de una Federación de Pósitos de la que se le había excluido, actuación de la que responsabiliza a Meléndez y la campaña desconsiderada que lidera contra su persona.

En noviembre, Costa se traslada a Bilbao para participar en una reunión que se celebrará en el Ministerio de Industria y Comercio, con el objeto de apoyar la candidatura del Marqués de Valterra a la Jefatura del Instituto Social de la Marina, por iniciativa y orden del propio Pascual Díez de Rivera; Costa Alonso recuerda así aquella actuación:

${ }^{34}$ Ibídem, pag. 77.

"CUADERNOS DE ESTUDIOS GALLEGOS", Tomo XLVI, Fascículo 111, Santiago 1999. 
«.........Ya en presencia del marqués me manifestó que me había llamado para decirme que yo le dijera al Ministro que lo nombrara y confirmara en el cargo de Jefe del Instituto Social de la Marina.

Celebramos la reunión, haciendo uso de la palabra, todos o casi todos los reunidos sobre distintos asuntos. Luego, ya al final, hablé yo, diciéndole al Ministro que en sustitución del gran hombre fundador de los Pósitos y eminente sociólogo, del que no teníamos noticia alguna, se hacía necesario nombrar a otro que, además de conocerla, sintiera la obra y los sufrimientos de los pescadores. Y al final-francamente lo confieso-me sentí muy satisfecho porque me pareció haber estado sereno y bastante bien. Luego, ya terminada la reunión, fui a ver al Marqués en la creencia de que lo hallaría también satisfecho y hasta pensé un momento en que me agradecería aquellas palabras que había pronunciado, sino con acierto, si con nobleza y sinceridad. Pero no fue así, ya que lo hallé bastante contrariado, manifestándome que no estaba contento de mi intervención, pues por poco -me dijohabla V de Saralegui y ya sabe que de ese hombre no se puede hablar Al oír esto de labios del Marqués, por quién tanto se había desvelado y tanto había defendido Saralegui en los tiempos difíciles de la República, mi asombro no tuvo límites» ${ }^{35}$.

El Instituto Social de la Marina, dirigido ya por el Marqués de Valterra, mantiene su sede en Santander,y la Mutualidad de Accidentes de Mar y de Trabajo, del que es responsable Augusto Bacariza, se traslada a Santiago de Compostela.

A comienzos de 1939 hay una gran desorientación sobre la probable fusión de los Pósitos y las entidades sindicales; los jerarcas sindicales del bando franquista persiguen el sometimiento de los Pósitos.

En marzo se concede el Subsidio de Vejez, y su ejecución puede ser competencia de los Pósitos o de la Delegación Sindical. Los Pósitos de Moaña y la Puebla de Caramiñal disputan entre sí el haber sido los primeros en pagar el Subsidio Familiar; mientras la Federación Gremial de Pósitos Marítimos, residente en Cambados y asesorada por Magariños y Meléndez, con escaso sentido resolutivo, todavía debate sobre esa ayuda económica.

${ }^{35}$ Ibídem, pag. 79

"CUADERNOS DE ESTUDIOS GALLEGOS", Tomo XLVI, Fascículo 111, Santiago 1999. 
A lo largo del año 1939 Costa Alonso recoge en su narración actuaciones que testimonian la incondicional protección del Marqués de Valterra hacia Meléndez: es el hecho de la inoperancia del Instituto Social de la Marina ante las denuncias de «anomalías e inmoralidades» cometidas por la Federación Gremial de Pósitos Marítimos, o la situación de desamparo en la que deja a Costa al apoyar la tramitación de un expediente promovido por Meléndez ante la actuación equívoca de los armadores de Moaña que hacen efectivo en el Pósito el pago de la compra de una partida de raba, dando pie a la sospecha de intermediación con ánimo de lucro. La conclusión del expediente deja libre de cargos al presidente moañés.

También en este último año de la guerra, se ratifica como ese aparato institucional que va surgiendo dentro del bando franquista pretende echar en el olvido la obra y la personalidad de Saralegui: en este caso un suelto publicado por Costa con motivo de la inauguración de la Casa del Pescador de Moaña, en el que invita a Saralegui, como fundador de los Pósitos Marítimos, y al Marqués de Valterra, es motivo de recriminación por el Jefe del Instituto Social de la Marina. Esta actuación llena de indignación a Costa, según se puede leer en sus Memorias:

«Antes de la inauguración, el 9 de dicho mes de noviembre, publiqué un suelto en Faro de Vigo, en el que, entre otras cosas, decía que a la inauguración de la Casa del Pescador de Moaña estaban invitados el fundador de los Pósitos Marítimos Sr. Saralegui y el Sr. Marqués de Valterra, habiendo llegado esto a conocimiento de este último, el cual según me informaron, se disgustó mucho por nombrar yo a Saralegui. ¡El Colmo!. Y don Joaquín Vidal, a los pocos días, me envió una carta un tanto amenazadora y fuera de tono, diciéndome que el Jefe del Instituto estaba disgustado que tuviera más disciplina, etc. Todo esto me puso violento al ver tamaña injusticia, enviándole un largo escrito a Vidal y otro al Marqués, haciendo el más franco y acalorado elogio del gran Saralegui.. $»^{36}$

${ }^{36}$ Apuntes de mi vida..., pag. 81 .

"CUADERNOS DE ESTUDIOS GALLEGOS", Tomo XLVI, Fascículo 111, Santiago 1999. 


\section{La gestión de la presidencia del Pósito}

El Pósito de Moaña inicia su andadura con importantes dificultades económicas La concesión de 2.000 pesetas por la Caja Central de Crédito Marítimo para la adquisición de material de enseñanza, supone una escasa inyección de vitalidad, de tal forma que el cierre de la Sociedad puede resultar inminente. Meses más tarde, gracias a las gestiones de Costa Alonso, la Caja Central de Crédito Marítimo le concede un préstamo de 5.000 pesetas para la compra de la lancha «María» y un arte de pesca al armador Manuel Cancelas Pena, que permiten la materialización de la cooperativa de producción. Esta cantidad es entregada al Tesorero, Balbino Pena Collazo, que, haciendo gala de una gran ignorancia sobre estas operaciones, se imagina que todo esto va a provocar su ruina. Narra Costa Alonso que con ese dinero le pagan 4.125 pesetas a Manuel Cancelas Pena, y con el dinero restante y algo más adquieren otro arte de pesca. La buena marcha de la contabilidad del Pósito y la excelente campaña pesquera del verano permiten amortizar, en total, la cantidad de 3.000 pesetas a la Caja de Crédito Marítimo. ${ }^{37}$

En 1923 las Secciones de Socorros Mutuos y Caja de Crédito y la organización general están encarriladas y exigen una importante dedicación del presidente en detrimento de su actividad personal, circunstancia que repercute negativamente en su economía doméstica y su relación familiar:

«Cuando recuerdo todo esto, acuden a mi imaginación recuerdos tristísimos, recuerdos de lucha, recuerdos de abandonos, de sufrimiento, de vicisitudes que no se explicar como yo quisiera.

Nadie me preguntaba como yo podía vivir, nadie me decía nada que pudiera servirme de consuelo» ${ }^{38}$.

A comienzos de 1924, Costa Alonso está preocupado por la repercusión que tiene en su vida familiar la dedicación a la organización del Pósito:

\footnotetext{
${ }^{37}$ Ibídem, pag. 14

${ }^{38}$ Ibídem, pag. 22
}

"CUADERNOS DE ESTUDIOS GALLEGOS", Tomo XLVI, Fascículo 111, Santiago 1999. 
«He aquí, pues, el problema que se me presentaba a principios de 1924 al entrar el Pósito en el tercer año de su vida. De una parte los intereses sagrados de la organización, por la cual había yo realizado tantos y tan grandes sacrificios. Y de otra parte los intereses, quizá más sagrados, de mi pobre familia que, por ocuparme del Pósito, tanto la he hecho sufrir y padecer, pues a pesar de haber apelado a medios imaginables, quiero hacer constar que mi honradez en la administración del Pósito, en la alta misión que reiteradamente se me había confiado, era austera en demasía». ${ }^{39}$

Sin embargo, todo ello no es obstáculo para que, en el relevo de cargos electos que hace la dictadura, acepte el cargo de concejal a propuesta del novísimo alcalde, Ernesto Carballo García; de cualquier forma la presencia de Costa Alonso en la gestión pública es breve, ya que es destituido en abril de 1924.

La carta de respuesta del Ayudante de Marina de Mazarrón, Gregorio Fernández Ballesta, al envío de la Memoria anual del Pósito, nos presenta a Costa Alonso como un hombre de la dictadura:

«........Querido amigo: He recibido la Memoria de ese Pósito Pescador y mucho le agradezco su atención y recuerdo.-Bien se ve, que si no prospera mucho, se debe a los malos tiempos de pesca, pues entusiasmo y competencia los hay sobrados-. Un Pósito así, con dirección tan acertada, con tan extremada moralidad económica, está llamado a grandes empresas, ayudando las circunstancias.- Recuerdo con mucha frecuencia y con mucho gusto a Vd y a tantos buenos y honorables pescadores amigos de la bellísima Moaña.-Continúe Vd. su apostólica labor, ya que el nuevo régimen es un estimulo y un apoyo para los hombres que como Vd. solo buscan el cumplimiento de los deberes y el mejoramiento de sus compañeros.... ${ }^{40}$

Dada la mala situación económica del Pósito en el verano de 1924, se acuerda solicitar de dicha Caja una ayuda de 200 pesetas que es concedida en sintonía con la promesa de ayuda de Saralegui en su visita a Moaña.

\footnotetext{
${ }^{39}$ Ibídem, pag. 28

${ }^{40}$ Apuntes de mi vida..., pag. 31
}

"CUADERNOS DE ESTUDIOS GALLEGOS", Tomo XLVI, Fascículo 111, Santiago 1999. 
En febrero de 1925 se materializa, mediante acuerdo de Junta General, la aspiración sentida desde hace tiempo de construir un local para el Pósito. Asimismo conviene señalar en este momento la expansión del Pósito de Moaña con la creación de una Sección en Tirán, para lo cual la Caja Central de Crédito Marítimo concede la correspondiente subvención. La inauguración se produce en septiembre de 1925, contando con lo necesario para poner en marcha las enseñanzas: materiales y el profesor, Ramiro Moure Moure.

A propuesta de Costa, en Junta General celebrada el 21 de octubre, se acuerda solicitar de la Caja Central de Crédito Marítimo un crédito de 10.000 pesetas para dotar mejor la sección «Caja de Crédito» y tener disponibilidad de mayor liquidez para los asociados.

En 1927 el Pósito de Moaña acuerda solicitar un préstamo importante para aumentar el capital de la Sección Caja de Crédito y poder proporcionar liquidez a aquellos armadores que quisieran poner motores a sus embarcaciones. De las gestiones a realizar, que se intuyen arduas y difíciles, se hace cargo Costa Alonso por presiones de los armadores, que incluso le prometen una gratificación para compensar el tiempo de desatención a su economía doméstica. La denegación del préstamo provoca el olvido de las promesas, la enemistad y la baja del Pósito de los armadores implicados, hecho del que se queja con cierta perplejidad Costa Alonso:

(....). «En vista de este fracaso los armadores que tan solemnemente me habían prometido abonarme lo que yo considerara justo con toda largueza, se negaron a ello, quedaron enemistados conmigo, sin tener culpa ninguna, y se dieron de baja en el Pósito, siendo todo ello muy lamentable, pues tal proceder no podía ser más injusto, cuando la causa solo estribaba en el criterio de los señores de la Caja Central, ya que no pagando los motores no era posible expedieran las casas certificado de ser de la propiedad de los armadores, pues precisamente para ello se solicitaba el préstamo, haciéndose, una vez pagados, nunca antes, la hipoteca....». ${ }^{41}$

\footnotetext{
${ }^{41}$ Ibídem, pag. 56
} 


\section{La actividad pesquera del Pósito}

En 1922 la actividad pesquera de la lancha del Pósito, una vez incorporados los armadores de «boliches» 0 «chinchorros», sigue una marcha ascendente, solo perturbada por las disensiones entre la tripulación y el patrón: «todos se creían con derecho a mandar y ninguno a obedecer, todos se consideraban dueños del barco y de las artes de pesca, y ninguno con la obligación de velar por su buen estado y conservación»; en un mal entendimiento de los objetivos del Pósito, creían que los artes de pesca y demás enseres serían para ellos, una vez amortizado el préstamo. Esta tensión se mantiene a lo largo del año, acentuada por el temor de los tripulantes más responsables de no poder devolver la deuda de 5000 pesetas a la Caja Central de Crédito Marítimo y tener que respaldarla con sus propios bienes. Por otra parte, en este momento, Costa Alonso se lamenta de la falta de honradez de algunos: «unas veces faltaban restos de «casca» (corteza de pino), otras veces faltaban cuerdas de esparto, otras leña, otras red, otros restos de salvado......, en fin el caos» ${ }^{42}$ Este ambiente de discordias permanentes provoca la marcha del patrón, José Parada y su sustitución por Antonio Costa Costa, que llega acompañado de una excelente campaña pesquera, coincidiendo con los meses del verano.

En septiembre de 1922 se necesita un barco mayor para ir a pescar a la costa de Portugal; se habla en el pueblo que los vapores «Febrero y Marzo» pueden ser tripulados por los socios del Pósito, hasta que ocurre el incendio del «Marzo», el mejor de los dos. Se hacen gestiones, sin éxito, con otros armadores para el uso de otra embarcación, y con el diputado por Redondelá, José Barreras Massó que niega su ayuda para conseguir un aparejo bueno. Para resolver la situación crítica que se genera porque, como es sabido, los socios tampoco son admitidos como tripulantes, el Pósito habilita el vapor «Fébrero», a pesar de que no reúne condiciones.

En el verano de 1923, Costa Alonso busca patrón para la trainera del Pósito con escasos resultados: en el caso de José Gayo, (Bocho), su rechazo se basa en una percepción negativa de la situación, «estaba esto muy mal». De cualquier forma, la solución no tarda en llegar: las gestiones realizadas para atender la costera de Leixoes llevaron a la contratación del vapor «Alianza», uno de los mejores barcos de la zona.

${ }^{42}$ Ibídem, pag. 14.

"CUADERNOS DE ESTUDIOS GALLEGOS", Tomo XLVI, Fascículo 111, Santiago 1999. 
A propuesta del presidente, en Junta General celebrada el 30 de marzo de 1924, se acuerda solicitar el uso libre del «chinchorro», «no solamente en las postas, sino también en todos los parajes». La respuesta es una concesión a medias: únicamente se permite el uso en las postas..

La nula actividad pesquera por falta de sardina resta posibilidades de amortización de la deuda, (en ese momento: 1750 pesetas), contraída con la Caja Central de Crédito Marítimo, de tal forma que en Junta General de 22 de junio se acuerda vender la lancha «María». Esta resolución se ratifica meses más tarde en la sesión de 26 de octubre, al dar el visto bueno a la venta de la embarcación y todos sus útiles de pesca por 3750 pesetas. La operación provoca la protesta y posterior baja de los socios tripulantes, que, en opinión de Costa Alonso, «se habían creído con derecho a repartirse caprichosamente esa cantidad, no dándose cuenta que los Pósitos son organizaciones ajenas a toda idea de lucro e ignorando lo que todavía se adeudaba... ${ }^{43} \mathrm{El}$ descontento de estos ex-socios degenera en una «campaña «contra Costa Alonso y el Pósito. Precisamente para desmontar esas acusaciones, en la Memorias se aportan datos contables donde se demuestra que, una vez deducidos gastos pendientes, solamente quedaría un resto de 900,05 pesetas que podrían ser repartidas entre los tripulantes, según un criterio poco ajustado a la significación de la sociedad cooperativa.

\section{Las enseñanzas}

El día 5 de junio se celebra la inauguración de las enseñanzas para los hijos de los asociados, coincidiendo con el primer aniversario de la constitución del Pósito. Asiste el Ayudante de Cangas que dirige la palabra a los concurrentes «que no subían de cincuenta». Costa Alonso pone en evidencia como actuación vergonzosa que muchos asistentes tuvieran «que llegar hasta el local del Pósito por los campos, y por debajo de las viñas ante el temor de ser descubiertos por los de la Alianza Marinera».

Dentro del capítulo de designación de responsables de la enseñanza, en el año de 1924 se dan pasos importantes: en Junta General de 17 de agosto se dispone el nombramiento de auxiliar de la escuela a José Chamadoira Alonso, y meses más tarde se resuelve la plaza de maestro, ocupada

${ }^{43}$ Ibídem, pag. 39

"CUADERNOS DE ESTUDIOS GALLEGOS", Tomo XLVI, Fascículo 111, Santiago 1999. 
interinamente y de manera irregular por Francisco Juncal Currás, padre del maestro titular desde 1922, Manuel Jesús Juncal Paredes. Según el testimonio de Costa Alonso la provisión de la plaza estuvo jalonada por actitudes caciquiles, superadas con tenacidad por el presidente, que al fin consigue el nombramiento del candidato con mayores méritos, Manuel Sueiro da Riva, quien no tarda mucho en dejar el puesto después de haber solicitado una interinidad «en forma canallesca, ocultamente», en el mes de octubre de 1925; a los pocos días de su partida Augusto Bouzas Lois se hace cargo de la escuela, que pocos meses más tarde ha de abandonar por enfermedad.

Durante el año 1936 nos cuenta Costa Alonso que tiene que enfrentarse con los nuevos maestros de las escuelas de los Pósitos de los pueblos más cercanos a Moaña, excepto el de Darbo, por «extender»su política de izquierda. Esta actuación repercute en una bajada en la valoración del presidente de Moaña, a quién los pescadores ven «como un elemento contrario a sus aspiraciones, fanatizados por propagandas de violencia...».

Costa se extiende en el comentario sobre estas actuaciones y acaba definiendo su posición ante la República:

«Ponía yo empeño en no prestar atención a todas esas campaña, esforzándome en aparentar una indiferencia, que realmente no se ajustaba a la realidad, tratando solo de llevar a buen término mi misión de inspector (....), creyendo haber hecho lo contrario que hacían los maestros (...). Mas por mucho que aparentara imparcialidad, principalmente cuando en reuniones se hablaba de ciertas cosas que consideraba sagradas, una y otra vez, aunque luego me arrepintiera de ello, hablaba mal contra el régimen y contra los que simpatizaban con él, no solamente en los puertos, sino también hasta en Madrid, por lo que en repetidas ocasiones se me llamó la atención». ${ }^{44}$

\section{La ayuda mutua}

En 1923 la Sección de Socorros Mutuos del Pósito tiene en su haber actuaciones benéficas para los socios: donativos a enfermos y préstamos concedidos con el aval de documentos justificativos. A la altura de la pri-

${ }^{44}$ Apuntes de mi vida....., pag. 57.

"CUADERNOS DE ESTUDIOS GALLEGOS", Tomo XLVI, Fascículo 111, Santiago 1999. 
mavera de 1924 los auxilios prestados a pescadores pobres y sus familiares contribuyen a extender su fama por otros puertos. En ese tiempo el área mutualista del Pósito de Moaña socorre a la familia de los náufragos de Bueu con 100 pesetas, que son entregadas por Enrique Bello, Ayudante de Marina en esa villa, acompañado de Gaspar Massó y los corresponsales de «Galicia» $\mathrm{y}$ «Faro de Vigo». ${ }^{45}$

En Junta General, celebrada el 30 de marzo de 1924, se acuerda que el Pósito se adhiriera al Seguro Mutuo de Ahogamiento.

En el año 1925 la Caja Central de Crédito Marítimo es autorizada para conceder subvenciones a las Secciones de Socorros Mutuos de los Pósitos, lo cual supone un espaldarazo a la actividad mutualista del de Moaña. ${ }^{46}$.

En el mes de mayo, el Pósito para paliar las consecuencias económicas del naufragio de la lancha «Peregrina», propiedad de José Sequeiros Rouco, Tesorero del Pósito, realiza una colecta, cuya recaudación se repartiría a partes iguales entre las tres familias afectadas; a esto hay que añadir, en el caso de los herederos de Sequeiros Rouco. la aportación del Seguro Mutuo de Ahogamiento, al que el Pósito está adherido.

A partir de la creación por el Secretariado Cooperativo de su sección, la Mutualidad de Accidentes de Mar y de Trabajo, paulatinamente y con dificultades se va extendiendo el establecimiento de Delegaciones en Galicia. El Instituto Social de la Marina no ceja en el empeño de poner en funcionamiento la Sección de Socorros Mutuos en todos los Pósitos, aunque las dificultades sean casi insuperables. ${ }^{47}$

En 1934, como ya hemos visto, se modifica la normativa sobre primas del Reglamento de la Mutualidad de Accidentes de Mary de Trabajo, que a partir de ahora son satisfechas del monte mayor y no por el armador.

\footnotetext{
${ }^{45}$ Ibídem, pag. 32.

${ }^{46}$ Ibídem, pag. 43.

${ }^{47}$ Ibídem, pag. 61 .
}

"CUADERNOS DE ESTUdIOS GALLEGOS", Tomo XLVI, Fascículo 111, Santiago 1999. 